\title{
Use of the plasma CTX for assessing the bone activity of the mandible among osteopenic and osteoporotic patients
}

\section{Glacio Avolio(a) Cynthia Brandão(b) Marcelo Marcucci(a) Gilberto Alonso(c)}

(a) PhD; (c)PhD, Associate Professor - Imaging Department, Federal University of São Paulo, São Paulo, SP, Brazil.

(b) PhD, Collaborating Physician Endocrinology Department, Federal University of São Paulo, São Paulo, SP, Brazil.

\author{
Corresponding author: \\ Marcelo Marcucci \\ Rua Pirapora, 248, Paraíso \\ São Paulo - SP - Brazil \\ CEP: 04008-060 \\ E-mail:marcucci21@gmail.com
}

Received for publication on Mar 24, 2010 Accepted for publication on May 13, 2010

\begin{abstract}
The aim of this study was to determine whether the plasma CTX bone remodeling marker is useful for indicating the bone metabolic activity level of the mandible. Thirty-six patients were selected; all were postmenopausal and aged 50 years or over. In accordance with the WHO criteria for osteoporosis, a control group was set up $(\mathrm{n}=10)$ in which the T-score was greater than -1 and a diseased group with Tscore less than -1 . Using MDP- ${ }^{99} \mathrm{~m}$ Tc samples, the radioisotope uptake in the femoral neck $\left(\mathrm{R}_{2}\right)$ and mandibular body $\left(\mathrm{R}_{1}\right)$ was analyzed. A third examination was performed using the plasma CTX biochemical bonemodeling marker. The inferential results for the diseased group showed that $\operatorname{Ln}\left(\mathrm{R}_{1}\right)$ presented a statistically significant linear relationship with $\operatorname{Ln}(C T x)(p=0.067)$ and with the T-score $(p=0.018)$. The plasma CTX bone remodeling marker is useful for monitoring the bone metabolic activity of the mandible.
\end{abstract}

Descriptors: Biological markers; Bone diseases, metabolic; Mandible.

\section{Introduction}

Osteoporosis is a disease of the skeleton characterized by decreased bone mineral density (BMD). This compromises the bone tissue microarchitecture and predisposes the individual to increased risk of fracture. ${ }^{1}$ The World Health Organization (WHO) has defined osteoporosis in white women as any bone mineral density measurement that is 2.5 standard deviations or more (T-score $<-2.5$ ) below the expected value for healthy young individuals (20-45 years of age). ${ }^{2}$ Patients with diminished bone mass frequently undergo anti-reabsorptive therapy using bisphosphonates, which have a significant modifying effect on bone turnover, and such patients may present a suppressed capacity for remodeling. ${ }^{3}$

The mandibular bone mass is subject to the same influences as the remainder of the skeleton and is affected by the action of the drugs used in treating osteoporosis. ${ }^{4}$ Thus, for dentists to be able to decide whether it is opportune to intervene surgically in relation to bone tissue, the degree of bone modeling occurring in maxillary bones needs to be known ${ }^{5}$. The greatest fear is osteonecrosis of the jaws, ${ }^{6,7}$ particulary for those patients that have used bisphosphonates intravenously for treating metastatic cancer disease of bones such as breast cancer, multiple myeloma and prostatic cancer. It is in this respect that the use of biochemical markers for bone remodeling may contribute towards this analysis. 
The biochemical bone reabsorption marker known as plasma CTX ${ }^{8}$ allows dynamic assessment of the level of bone tissue remodeling based on analysis of carboxyterminal telopeptide fragments of type I collagen that result from osteoclastic ${ }^{9}$ action occurring within the bone matrix on its crosslinkforming interlinking molecules, pyrrolidine (PYD) and deoxypyrrolidine (DPD). This marker presents better histomorphological ${ }^{10}$ correlations with the remodeling changes that occur in the bone tissue. It is a test that is easy to perform, with minimal discomfort for patients and without exposure to ionizing radiation, and it can be repeated whenever requested, without requiring a large time interval since the previous examination. This is in contrast with the bone densitometry examination, for which a minimum time interval of six months to one year is required in order to detect a possible change in bone mass.

A bone scintigraphy examination was performed with the aim of determining the level of radioisotope uptake in the regions of the femoral neck and the mandibular body, in order to observe any possible functional abnormalities related to remodeling. ${ }^{11,12}$

The aim of the present study was to determine the effectiveness of using plasma CTX, a biochemical marker for bone remodeling, in assessing the bone metabolic activity level of the mandible.

\section{Method \\ Subjects}

For this study, 36 postmenopausal female patients aged 50 years or over were selected and divided into two groups. The first group consisted of 26 patients who presented diminished bone mineral density (among whom 14 were using alendronate): 16 were considered to be osteopenic, with T-scores of less than -1 and greater than or equal to -2.5 , and 10 were considered to be osteoporotic, with T-scores of less than -2.5 , thus following the WHO criteria for osteoporosis. ${ }^{1}$ The second group was formed by 10 individuals who were considered to be normal. All these individuals were selected retrospectively from the database of the osteoporosis outpatient clinic of the Department of Endocrinology of the Federal University of São Paulo (UNIFESP).

Patients presenting diseases that might have af- fected their bone mass, such as chronic renal insufficiency, hyperparathyroidism, hyperthyroidism or liver disease, were excluded from this investigation. Likewise, patients were excluded if they presented any type of neoplasia, because of the possibility that bone metastasis could have occurred. ${ }^{7}$ The use of corticoids and anti-convulsive ${ }^{13}$ medications was also an exclusion criterion.

Following an oral cavity examination, only the patients with no teeth at all or with no teeth in the region of the mandibular body were selected. This was done in order to avoid local causes that might interfere with the bone reabsorption in these regions. This study gained prior approval from the Research Ethics Committee of the Federal University of São Paulo, and all the subjects voluntarily agreed to participate in the study.

\section{Bone densitometry examination}

Bone densitometry examination using DXA (Dual Energy X-ray Absorptiometry) was used as the criterion for selecting the patients with abnormal and normal bone mass.

All the patients were positioned in horizontal dorsal decubitus for the bone mineral density (BMD) measurement. The examinations were all performed using the DPX-L apparatus (Lunar, Madison, California, USA), coefficient of variation (CV) with aluminiun phantom is $1 \%$, and the DPX-IQ software, version 4.7 (Lunar, Madison, California, USA). Readings were made in the region of the neck of the right femur. We chose to compare the femoral neck with the region of the mandibular body because the anatomical structure of the femoral neck is more corticalized and in this respect resembles the mandible, whereas the vertebral structures are predominantly trabecular. ${ }^{14,15}$

\section{Bone scintigraphy examination}

In order to observe any possible functional abnormalities related to remodeling ${ }^{12}$ a bone scintigraphy examination was performed. Hence, around $1 \mathrm{ml}$ of radiolabeled agent containing MDP- ${ }^{99 \mathrm{~m}} \mathrm{Tc}$ equivalent to $30 \mathrm{mCi}$ was administered endovenously. ${ }^{11}$ The images were acquired by means of the LFOV single-head APEX SPX4 apparatus (Elscint, 
Haifa, Israel). With the aim of avoiding reading errors due to background radiation coming from soft tissue, an index was established based on the ratio between the scintillation count observed in the bone tissue and the count in the soft tissue adjacent to the Region of Interesting (ROI) under examination. For the region of the femur, this area corresponded to the lateral part of the thigh and, for the region of the mandible, this area selected was the retromolar region beside the soft tissue of the adjacent lateral cervical area. Thus, two indices named $R_{1}$ and $R_{2}$ were obtained, referring respectively to the mandible and the femur.

\section{Plasma CTX bone marker examination}

Biochemical markers for bone remodeling can be defined as substances that depict bone formation or reabsorption. ${ }^{9}$ It also better reflects the calcium kinetics and is sensitive to small changes in the bones like those that occur over the course of osteoporosis. ${ }^{16}$ Because bone remodeling markers are subject to circadian ${ }^{17}$ influence, the time of day for data collection was standardized such that the patients were always asked to come at the start of the morning, after having fasted for eight hours.

\section{Statistical analysis}

Twenty-six patients with diminished bone mass were selected, among whom 14 were using alendronate. The group of patients who were considered to be osteopenic or osteoporotic were analyzed together because what was important was the fact that they presented bone mass abnormalities, regardless of the extent, for comparison with the normal group. The relationships between $\mathrm{R}_{1}$, $\mathrm{T}$-score and CTX were analyzed by means of multiple logistic regression, and regression models were adjusted for each of the groups considered. The relationship between $\mathrm{R}_{1}$ and CTX was analyzed by means of simple linear regression. With the aim of bringing the values closer together and diminishing the variability among the data gathered in this study, the resource of Naperian logarithms (which is frequently used in statistical analysis) was applied, with the aim of obtaining a relationship that was more linear, since such relationships are easier to analyze.
The SPSS for windows 11.5 (SPSS Inc., Chicago, Illinois, USA) was used for carrying out the statistical analysis. In all cases, the level for rejecting the nullity hypothesis was always set at the level of $\mathrm{p} \leq 0.10(10 \%)$, and statistically significant values were marked with an asterisk (*).

\section{Results}

Dispersion and boxplot graphs were constructed, which depict the distribution of the magnitudes in the two study groups (Graphs 1 and 2). It is important to emphasize that the T-score only provides the bone mineral density value obtained at the time of the examination, which does not necessarily reflect the true metabolic condition of the bone tissue, as can be seen in the dispersion graph (Graph 1).

Given the nature of the variables studied, summary measurements were calculated (Tables 1, 2 and 3).

The inferential results for the diseased group of patients showed that $\operatorname{Ln}\left(\mathrm{R}_{1}\right)$, i.e. the Naperian loga-

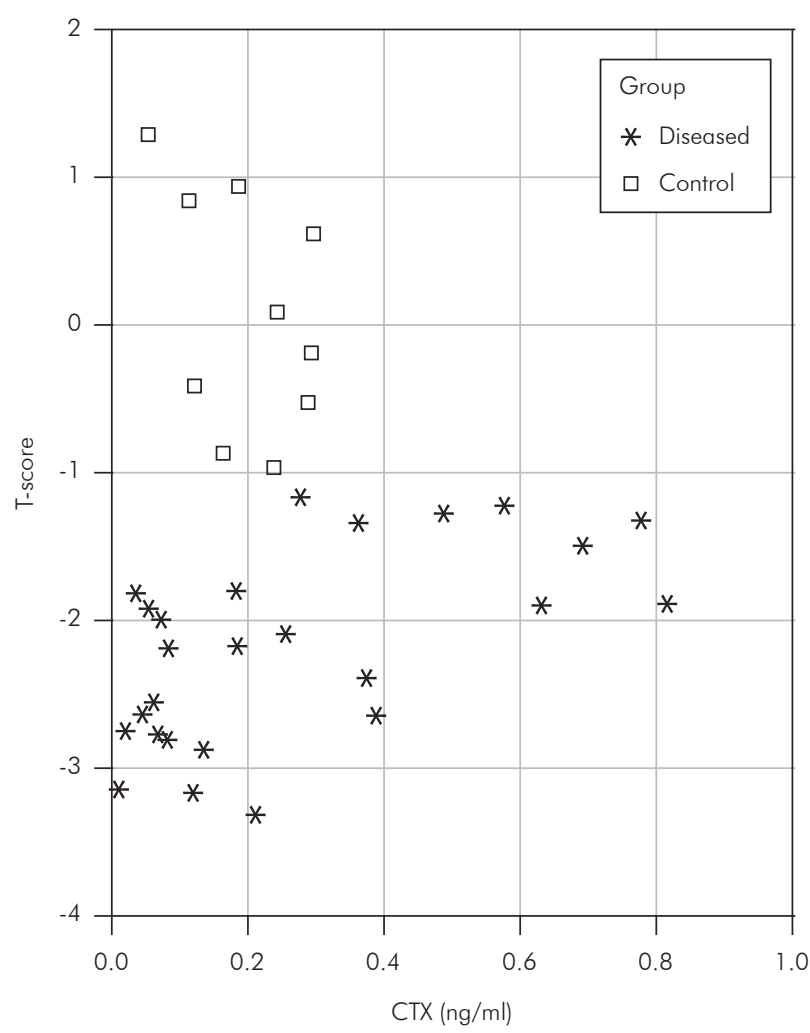

Graph 1 - CTX and T-score dispersion graph for the two groups. 
Table 1 - Measurements for age, mandible, soft tissue and $R_{1}$, for the two study groups.

\begin{tabular}{|c|c|c|c|c|c|c|c|c|}
\hline \multirow{2}{*}{ Measur. } & \multicolumn{2}{|c|}{ Age } & \multicolumn{2}{|c|}{ Mandible } & \multicolumn{2}{|c|}{ Soft tissue } & \multicolumn{2}{|c|}{$R_{1}$} \\
\hline & Control & Diseased & Control & Diseased & Control & Diseased & Control & Diseased \\
\hline $\mathrm{N}$ & 10 & 26 & 10 & 26 & 10 & 26 & 10 & 26 \\
\hline Mean & 58.80 & 67.54 & 11549.50 & 13281.50 & 6901.60 & 7452.35 & 1.69 & 1.84 \\
\hline SD & 4.85 & 9.51 & 1810.24 & 2138.34 & 1439.07 & 1404.32 & 0.13 & 0.45 \\
\hline Minimum & 51.00 & 51.00 & 8390.00 & 8328.00 & 4801.00 & 4883.00 & 1.46 & 1.21 \\
\hline Maximum & 68.00 & 85.00 & 14253.00 & 18053.00 & 9785.00 & 9785.00 & 1.86 & 2.89 \\
\hline
\end{tabular}

$\mathrm{N}=$ sample size $; \mathrm{SD}=$ standard deviation; Measur $=$ measurements.

Table 2 Measurements for the femur, thigh and $R_{2}$, in the two study groups.

\begin{tabular}{c|c|c|c|c|c|c}
\hline \multirow{2}{*}{ Measur. } & \multicolumn{2}{|c|}{ Femur } & \multicolumn{2}{c|}{ Thigh } & \multicolumn{2}{c}{$\mathrm{R}_{2}$} \\
\cline { 2 - 7 } & Control & Diseased & Control & Diseased & Control & Diseased \\
\hline $\mathrm{N}$ & 10 & 26 & 10 & 26 & 10 & 26 \\
\hline Mean & 9192.80 & 10028.31 & 2798.90 & 3616.88 & 3.36 & 2.94 \\
\hline SD & 2607.46 & 2106.24 & 542.70 & 764.63 & 0.91 & 1.09 \\
\hline Minimum & 6440.00 & 6644.00 & 1567.00 & 2473.00 & 2.10 & 1.51 \\
\hline Maximum & 12799.00 & 14802.00 & 3269.00 & 4804.00 & 4.47 & 5.72 \\
\hline
\end{tabular}

$\mathrm{N}=$ sample size; $\mathrm{SD}=$ standard deviation; Measur $=$ measurements.

Table 3 Measurements for BMD/neck, T-score/ neck, and CTX, in the

two study groups.

\begin{tabular}{c|c|c|c|c|c|c}
\hline \multirow{2}{*}{ Measur. } & \multicolumn{2}{|c|}{ BMD/neck } & \multicolumn{2}{c|}{ T-score/neck } & \multicolumn{2}{c}{ CTX (ng/ml) } \\
\cline { 2 - 7 } & Control & Diseased & Control & Diseased & Control & Diseased \\
\hline $\mathrm{N}$ & 10 & 26 & 10 & 26 & 10 & 26 \\
\hline Mean & 0.99 & 0.73 & 0.09 & -2.18 & 0.20 & 0.27 \\
\hline SD & 0.10 & 0.08 & 0.80 & 0.65 & 0.08 & 0.25 \\
\hline Minimum & 0.86 & 0.58 & -0.97 & -3.33 & 0.05 & 0.01 \\
\hline Maximum & 1.18 & 0.92 & 1.30 & -1.15 & 0.30 & 0.81 \\
\hline
\end{tabular}

$\mathrm{N}=$ sample size; $\mathrm{SD}=$ standard deviation; Measur = measurements.

rithm of $\mathrm{R}_{1}$, presented a statistically significant linear relationship with $\operatorname{Ln}(\mathrm{CTx})$ (Naperian logarithm of CTx) ( $\mathrm{p}=0.067)$ and with the T-score ( $\mathrm{p}=0.018)$, as can be seen in the summary of the inferential results (Table 4).

The boxplot graphical analysis considering the CTX values for the two groups of patients (Graph 2) showed that there was a more homogenous distribution for the control group. On the other hand, for the group of patients with BMD abnormalities (diseased group), the distribution was less homogenous and this observation was compatible with the varying amounts of CTX that were released into the bloodstream and detected by this type of test.
Thus, it could be seen from the dispersion graph (Graph 1) that the relationship between the metabolic activity of the mandible $\left(\mathrm{R}_{1}\right)$ and the CTX values among the diseased individuals (both expressed in the form of Naperian logarithms) presented statistical significance, with a descriptive level of $\mathrm{p}=0.067$ for this sample of 26 diseased patients.

Thus, for the diseased group, the value of $\operatorname{Ln}\left(\mathrm{R}_{1}\right)$ can be calculated from the $\mathrm{T}$-score and $\mathrm{Ln}(\mathrm{CTx})$, by means of the regression equation:

$\operatorname{Ln}\left(\mathrm{R}_{1}\right)=0.300-0.200 \times$ Tscore $+0.082 \times \operatorname{Ln}(\mathrm{CTx})$

The following is the interpretation from the pa- 
Table 4 - Inferential results from the multiple linear regression model for the diseased group compared to $\operatorname{Ln}\left(R_{1}\right)$.

\begin{tabular}{c|c|c|c}
\hline Model & Coefficients & Standard error & Descriptive level $(p)$ \\
\hline Constant & 0.300 & 0.147 & $0.053^{*}$ \\
\hline T-score & -0.200 & 0.078 & $0.018^{*}$ \\
\hline $\operatorname{Ln}(\mathrm{CTx})$ & 0.082 & 0.042 & $0.067^{*}$ \\
\hline
\end{tabular}

Ln $=$ Naperian logarithm of CTX. ${ }^{*}$ Statistically significant values are marked with an asterisk.

rameters calculated in the above equation: The decrease in $\operatorname{Ln}\left(\mathrm{R}_{1}\right)$ for each one-unit increase in the T-score is -0.200 ; The increase in $\operatorname{Ln}\left(\mathrm{R}_{1}\right)$ for each one-unit increase in $\operatorname{Ln}(\mathrm{CTx})$ is 0.082 . The results from adjusting the regression model for the control group showed that $\mathrm{T}$-score ${ }^{2}$ (square of the T-score) $(\mathrm{p}=0.038)$ and $\operatorname{Ln}(\mathrm{CTx})(\mathrm{p}=0.172)$ were linearly associated with $\operatorname{Ln}\left(\mathrm{R}_{1}\right)$.

\section{Discussion}

The mandible body area was elected in order to avoid anatomical overlapping structures and also being a region of greater remodelative stimulus, due to the insertion of muscles, and therefore subject to greater metabolic influence. ${ }^{12,18}$ The reason why an edentulous area was chosen was to avoid the possibility of irritative local factors such as periodontal disease, poorly adapted prostheses or dental anomalies (thus not a result from a metabolic systemic source) that could in any way represent a local factor of absorption and interfere in the rate of radioisotope uptake. Nevertheless, it is supposed that the same metabolic systemic influences also may occur in the upper jaw and in toothed patients.

In analyzing the radioisotope uptake rates (Tables 1 and 2), it was observed that $R_{1}$ was around 1.5 times smaller than $R_{2}$. This is due to the fact that the femoral neck is subject to the action of greater loads than experienced by the mandible, and also because it presents greater bone volume. It was also observed that the $\mathrm{R}_{1}$ index was more heterogenous in the diseased group than in the control group, which can be explained by the fact that many of these diseased patients (14 individuals) presented low bone turnover because they were using anti-reabsorptive medication, thereby giving rise to this effect in the

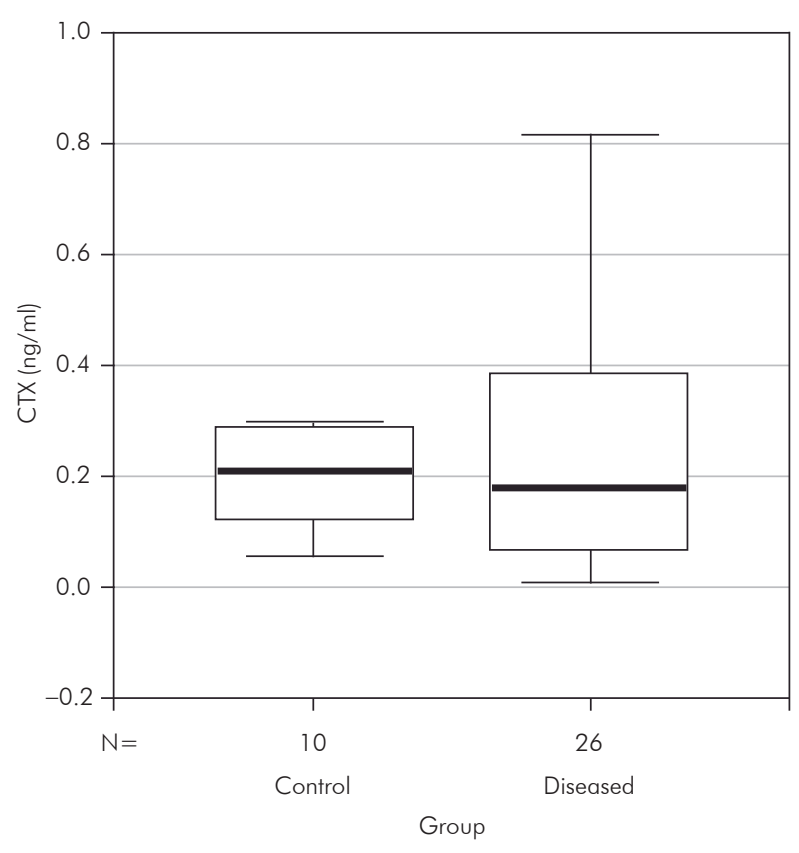

Graph 2 - Boxplot of CTX for the control and diseased groups.

analysis for this group. The same can be seen in the analysis on the $R_{2}$ index, although this presented a higher median value because of the abovementioned reasons. In this group, for $\mathrm{T}$-score values close to the limit of normality, high CTX values (normal reference values for male: $0.300 \mathrm{ng} / \mathrm{ml} 30-50$ years; $0.304 \mathrm{ng} / \mathrm{ml} 50-70$ years; $0.394 \mathrm{ng} / \mathrm{ml}>70$ years and female: $0.299 \mathrm{ng} / \mathrm{ml}$ premenopausal; $0.556 \mathrm{ng} /$ $\mathrm{ml}$ postmenopausal $)^{19,20}$ can be seen, thus indicating a high degree of bone reabsorption. On the other hand, T-score values that are considered low, as a result of possible elevation of resorptive activity that characterizes low BMD, present low CTX values that come close to zero as a consequence of the low level of bone remodeling. This can be explained by the use of anti-reabsorptive agents.

The CTX values for the diseased group (Graph 1) were shown to be coherent with the clinical findings and ranged from values close to zero (explained by the use of anti-reabsorptive medication) to high values of CTX among the patients who were not using alendronate but presented a high degree of bone remodeling.

All this evidence is concordant with the literature, ${ }^{21}$ in which CTX is indicated as an efficient and 
reliable clinical method for monitoring not only the metabolic activity of bone tissue but also the therapeutic efficacy of the drugs used in treating osteoporosis. ${ }^{13,22}$ It is important to emphasize that correlations must be made while always taking into account each patient's clinical information since, otherwise, errors may be made in interpreting the data. In the light of patient populations that are subject to factors that compromise their bone metabolism, it becomes necessary to assess the level of the

\section{References}

1. Lewiecki EM, Binkley N. Evidence-based medicine, clinical practice guidelines, and common sense in the management of osteoporosis. Endocr Pract. 2009 Sep-Oct;15(6):573-9.

2. Kanis JA, Melton LJ, Christianse C, Johnston CC, Khaltaev N. The diagnosis of osteoporosis. J Bone Miner Res. 1994 Aug;11(8):1199-201.

3. Hughes DE, Wright KR, Uy HL, Sasaki A, Yoneda T, Roodmam GD, et al. Bisphosphonates promote apoptosis in murine osteoclasts in vitro and in vivo. J Bone Miner Res. 1995 Oct;10(10):1478-87.

4. Kribbs PJ, Chesnut CH III, Ott SM, Kilkoyne RF. Relationships between mandibular and skeletal bone in an population of normal women. J Prosthet Dent. 1990 Jan;63(1):86-9.

5. Von Wowern N, Klausen B, Kollerup G. Osteoporosis: a risk factor in periodontal disease. J Periodontol. 1994 Dec;65(12): 1134-8.

6. Marx R. Pamidronate (Aredia) and zoledronate (Zometa) inducci avascular necrosis of the jaws: a growing epidemic. J Oral Maxillofac Surg. 2003 Sep;61(9):1115-7.

7. Bagan JV, Murillo J, Jimenez Y, Poveda R, Milian MA. Avascular jaw osteonecrosis in association with cancer chemotherapy: series of 10 cases. J Oral Pathol Med. 2005 Feb;34(2):120-3.

8. Garnero P, Borel O, Delmas PD. Evaluation of a Fully Automated Serum Assay for C-Terminal Cross-Linking Telopeptide of Type I Collagen in Osteoporosis. Clin Chem. 2001 Apr;47(4):694-702.

9. Vieira JG. Considerações sobre os marcadores bioquímicos do metabolismo ósseo e sua utilidade prática. Arq Bras Endocrinol Metabol. 1999 Dez;43(6):415-22.

10. Bikle DD. Biochemical markers in the assessment of bone disease. Am J Med. 1997 Nov;103(5):427-36.

11. Donohoe KJ, Henkin RE, Royal HD, Brown ML, Collier $\mathrm{BD}$, Omara RE et al. Procedure guidelines for bone scintigraphy: 1.0 Society of Nuclear Medicine. J Nucl Med. 1996 Nov;37(11):1903-6. metabolic activity of their bone tissue, independent of the BMD values that they may present.

\section{Conclusion}

This result makes it possible for us to state that the plasma CTX test is useful for estimating the bone metabolic activity of the mandible. Further studies are necessary to understand the role played by the use of anti-reabsorptive medication on the jaws.

12. Fogelman I, Collier BD, Brown ML. Bone scintigraphy; part 3. bone scanning in metabolic bone disease. J Nucl Med 1993 Dec; 34(12):2247-52.

13. Livingston S, Berman W, Pauli LL. Anticonvulsivant Drugs and Vitamin D Metabolism. JAMA. 1973 Jun;224(12):1634-5.

14. Haller J, André MP, Resnick D, Miller C, Howard SA, Mitchell MJ. Detection of thorocolumbar vertebral body destruction with lateral spine radiography. Part I: Investigation in cadavers. Invest Radiol. 1990 May;25(5):517-22.

15. Rey C, Combes C, Drouet C, Glimcher MJ. Bone mineral: an update on chemical composition and structure. Osteoporos Int. 2009 Jun;20(6):1010-21.

16. Seibel MJ. Molecular Markers of bone turnover: biochemical, technical analytical aspects. Osteoporos Int. 2000; 11 Suppl 6:S18-29.

17. Heshmati HM, Riggs BL, Burrit MF, McAlister CA, Wollan PC, Khosla S. Effects of the circadian variation in serum cortisol on markers of bone turnover and calcium homeostasis in normal postmenopausal women. J Clin Endocrinol Metab. 1998 Mar;83(3):751-6.

18. Mulligan R, Sobel S. Osteoporosis: diagnostic testing, interpretation, and correlations with oral health-implications for dentistry. Dent Clin North Am. 2005 Apr;49(2):463-84.

19. Garnero P, Delmas PD. Biochemical markers of bone turnover - applications for Osteoporosis. Endocrinol Metab Clin North Am. 1998 Jun;27(2):303-23.

20. Garnero P, Sornay-Rendu E, Duboeuf F, Delmas F. Markers of Bone Turnover Predict Postmenopausal Forearm Bone Loss Over 4 Years: The OFELY Study. J Bone Miner Res. 1999 Sep;14(9):1614-21.

21. Marx RE, Cillo JE, Ulloa JJ. Oral Bisphosphonate-Induced Osteonecrosis: Risk Factors, Prediction of Risk Using Serum CTX Testing, Prevention, and Treatment. J Oral Maxillofac Surg. 2007 Dec;65(12):2397-410.

22. Blumsohn A, Eastell R. The performance and utility of biochemical markers of bone turnover: do we know enough to use them in clinical practice? Ann Clin Biochem. 1997 Sep;34(Pt5):449-59. 